\title{
Large and variable genome size unrelated to serpentine adaptation but supportive of cryptic sexuality in Cenococcum geophilum
}

\author{
Elizabeth C. Bourne • Diogo Mina • \\ Susana C. Gonçalves • João Loureiro • \\ Helena Freitas • Ludo A. H. Muller
}

Received: 2 January 2013 / Accepted: 17 April 2013 / Published online: 11 June 2013

(C) Springer-Verlag Berlin Heidelberg 2013

\begin{abstract}
Estimations of genome size and its variation can provide valuable information regarding the genetic diversity of organisms and their adaptation potential to heterogeneous environments. We used flow cytometry to characterize the variation in genome size among 40 isolates of Cenococcum geophilum, an ectomycorrhizal fungus with a wide ecological and geographical distribution, obtained from two serpentine and two non-serpentine sites in Portugal. Besides determining the genome size and its intraspecies variation, we wanted to assess whether a relationship exists between genome size and the edaphic background of the $C$. geophilum isolates. Our results reveal C. geophilum to have one of the largest genome sizes so far measured in the Ascomycota, with a mean haploid genome size estimate of 0.208 pg (203 Mbp). However, no relationship was found between genome size and the edaphic background of the sampled isolates, indicating genetic and demographic processes to be more important for shaping the genome size variation in this species than environmental selection. The detection of variation in ploidy level among our isolates,
\end{abstract}

Elizabeth C. Bourne and Diogo Mina contributed equally to this work.

Electronic supplementary material The online version of this article (doi:10.1007/s00572-013-0501-3) contains supplementary material, which is available to authorized users.

E. C. Bourne • D. Mina • S. C. Gonçalves · J. Loureiro •

H. Freitas $\cdot$ L. A. H. Muller

Centre for Functional Ecology, Department of Life Sciences,

University of Coimbra, 3001-401 Coimbra, Portugal

E. C. Bourne $\cdot$ L. A. H. Muller $(\bowtie)$

Institut für Biologie - Botanik, Freie Universität Berlin,

Altensteinstraße 6,

14195 Berlin, Germany

e-mail: ludo.muller@fu-berlin.de including a single individual with both presumed haploid and diploid nuclei, provides supportive evidence for a possible cryptic sexual or parasexual cycle in C. geophilum (although other mechanisms may have caused this variation). The existence of such a cycle would have wide significance, explaining the high levels of genetic diversity and likelihood of recombination previously reported in this species, and adds to the increasing number of studies suggesting sexual cycles in previously assumed asexual fungi.

Keywords Cenococcum geophilum · Cryptic sexuality · Ectomycorrhizal fungi · Flow cytometry · Genome size . Serpentine soil

\section{Introduction}

Nuclear genome sizes vary tremendously between eukaryotic species (Whitney and Garland (2010) report a range spanning 8 orders of magnitude) and this variation is due to a multitude of processes, including polyploidization, gene duplication and amplification of transposable elements (see, e.g., Soltis and Soltis 1999; Cui et al. 2006; Kazazian 2004). Although these mutational processes can induce structural and functional changes that are assumed to promote further evolution and adaptation in plants, animals, and fungi, it is currently still under debate whether the variation in genome size between species is predominantly the result of adaptive or of neutral processes (see, e.g., Whitney and Garland 2010).

Besides variation in genome size between species, variation within species is also commonly observed. This withinspecies genome plasticity has been well studied in several fungal species where it has been found to be associated with 
life cycle or cellular differentiation and with changing environmental conditions (Albertin and Marullo 2012). For example, Candida albicans is a diploid yeast that frequently enters a cryptic mating or parasexual cycle in which somatic cells fuse and the resulting tetraploid cells undergo a random loss of chromosomes. As a result, a variety of ploidy levels, including aneuploidy, can be observed among C. albicans isolates (Ibrahim et al. 2005). Candida glabrata on the other hand is a haploid fungal species that displays frequent changes in its chromosome complement in relation with pathogenicity and a changing environment (Poláková et al. 2009). Specific environmental factors that have been shown to affect fungal genome size include salt stress (Dhar et al. 2011), fungicide treatments (Welker and Williams 1980), heat shock treatments (Hilton et al. 1985), and host-pathogen interactions (Raffaele and Kamoun 2012).

We aimed to investigate genome size in the ectomycorrhizal ascomycete Cenococcum geophilum Fr. and assess whether it is affected by serpentine edaphic conditions. Mycorrhizal fungi are a diverse group of soil microorganisms that form multifunctional symbiotic associations with the roots of vascular plants, in which the fungi aid nutrient and water uptake by the plant, improve plant tolerance to drought and pathogens, and aid plant performance in environments high in heavy metal content (Smith and Read 2008). C. geophilum, which associates with the roots of both gymnosperms and angiosperms in temperate to tropical regions (Trappe 1964), has become the focus of increased research effort, partly due to its broad geographic and ecological distribution (LoBuglio 1999). Although multilocus genotype assessments suggest the occurrence of recombination and a possible cryptic sexual cycle (Taylor et al. 1999, Lobuglio and Taylor 2002, Douhan et al. 2007), a sexual stage has so far been assumed to be absent in $C$. geophilum (although see Fernandez-Toiran and Agueda 2007, and Spatafora et al. 2012). While this absence would imply clonal reproduction and a relatively low genetic diversity, various studies have demonstrated an unexpectedly high level of genetic diversity within and between $C$. geophilum populations (e.g., Panaccione et al. 2001; Wu et al. 2005; Douhan et al. 2007; Gonçalves et al. 2007).

C. geophilum has been shown to be locally adapted to serpentine soil conditions (Gonçalves et al. 2007, 2009). Serpentine soils are widespread soils formed by the weathering of ultramafic rocks and typically have a low calcium-to-magnesium ratio, with calcium levels significantly lower compared to surrounding non-serpentine soils. In addition, they often contain relatively high concentrations of heavy metals such as chromium, cobalt, and nickel and low concentrations of essential nutrients such as nitrogen, potassium, and phosphorus, and are prone to drought. These edaphic conditions usually present a major challenge to exposed biota and may give rise to a unique flora and mycoflora (Proctor 1999; Panaccione et al. 2001), rendering serpentine soils into appealing systems for addressing mechanistic questions of adaptive evolution in natural environments (Brady et al. 2005). Although many studies have been performed on serpentine flora and systematics, natural history, ecology, and physiology, possible relationships between adaptation to serpentine soil conditions and genome size variation have not received much attention. Nevertheless, independent polyploid evolution in serpentine populations of Knautia arvensis (Dipsacaceae) that promoted further evolution of serpentine lineages has recently been reported (Kolář et al. 2012).

Here, we report on the genome size of C. geophilum and its naturally occurring variation as determined by flow cytometry analysis of 40 isolates obtained from two serpentine and two non-serpentine populations in the northeast of Portugal. We first present data describing variation in genome size occurring in this fungal species and discuss the implications of our findings in the context of adaptive evolution of serpentine tolerance. In addition, we show that our data provides support for a possible cryptic mating or parasexual cycle in C. geophilum.

\section{Material and methods}

Field sites and fungal material

Soil samples containing C. geophilum sclerotia were collected in two serpentine (S) and two non-serpentine (NS) Quercus ilex subsp. ballota woodlands, located in Trás-os-Montes, northeastern Portugal: Serra da Nogueira (serpentine, $41^{\circ} 47^{\prime}$ $58.98^{\prime \prime} \mathrm{N}, 06^{\circ} 54^{\prime} 15.55^{\prime \prime} \mathrm{W}$ ), Espinhosela (serpentine, $41^{\circ} 51^{\prime}$ $22.13^{\prime \prime} \mathrm{N}, 06^{\circ} 50^{\prime} 424.00^{\prime \prime} \mathrm{W}$ ), Rabal (non-serpentine, $41^{\circ} 52^{\prime}$ $14.88^{\prime \prime} \mathrm{N}, 06^{\circ} 44^{\prime} 40.00^{\prime \prime} \mathrm{W}$ ) and Aveleda (non-serpentine, $\left.41^{\circ} 52^{\prime} 08.41^{\prime \prime} \mathrm{N}, 06^{\circ} 41^{\prime} 58.97^{\prime \prime} \mathrm{W}\right)$.

To avoid multiple sampling of the same fungal genotype, soil samples were collected around oaks at least $5 \mathrm{~m}$ apart. After sieving and washing the soil samples, viable sclerotia (Trappe 1964) were manually picked, surface sterilized in $30 \%$ hydrogen peroxide for 10-20 s (Douhan and Rizzo 2005), rinsed in sterile water and transferred to Potato Dextrose Agar (PDA; Difco, Sparks, MD, USA) with streptomycin $(0.2 \mathrm{mg} / \mathrm{L})$ to germinate. The plates were incubated in the dark at room temperature and regularly observed for up to 1 month. Growing C. geophilum isolates were then subcultured on PDA without antibiotics and maintained in the dark at room temperature until further use.

Genome size estimation

The nuclear DNA content of $C$. geophilum was estimated by flow cytometry using fresh mycelium from young colonies. 
Propidium iodide (PI)-stained nuclei were extracted from ten in vitro-cultured isolates per population and the refer-

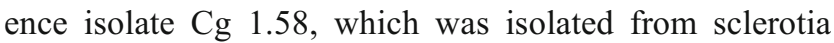
found in a Scots pine forest in Pfynwald VS by Martina Peter in 2008 and which was recently used in a study by Spatafora et al. (2012) on the phylogenetic placement of the genus Cenococcum within the family Gloniaceae. For each isolate, three independent replicate measurements were performed. Mycelium was collected with a needle and added to a Petri dish with $1 \mathrm{~mL}$ of modified woody plant buffer (WPB; $0.2 \mathrm{M}$ Tris- $\mathrm{HCl}, 4 \mathrm{mM} \mathrm{MgCl}{ }_{2} \cdot 6 \mathrm{H}_{2} \mathrm{O}, 2 \%$ Triton X-100, $2 \mathrm{mM}$ disodium EDTA, $86 \mathrm{mM} \mathrm{NaCl}, 20 \mathrm{mM}$ metabisulfite, $4 \%$ PVP-10, [pH 7.5]; Loureiro et al. 2007). Nuclei were released following the procedure of Galbraith et al. (1983) by chopping approximately $10 \mathrm{mg}$ of mycelium with a razor blade together with $50 \mathrm{mg}$ of fresh leaf tissue of Raphanus sativus (internal reference standard with $2 \mathrm{C}=$ $1.16 \mathrm{pg}$ or $1,135 \mathrm{Mbp}$; Doležel et al. 1998) to ensure that nuclei of both species were exposed to identical chemical and mechanical conditions.

The nuclear suspension was filtered through a $30 \mu \mathrm{m}$ nylon filter to remove large fragments, and $50 \mu \mathrm{g} / \mathrm{mL}$ of PI (Fluka, Buchs, Switzerland) together with $50 \mu \mathrm{g} / \mathrm{mL}$ of RNase (Fluka, Buchs, Switzerland) were subsequently added to respectively stain the nuclei and prevent staining of double-stranded RNA. After incubation for $5 \mathrm{~min}$, the fluorescence intensity of at least 2,000 nuclei per sample was analyzed using a Partec CyFlow Space flow cytometer (Partec GmbH, Görlitz, Germany), equipped with a green solid state laser for PI excitation. The $\mathrm{G}_{0} / \mathrm{G}_{1}$ peak of the standard was set to channel 720 , with the amplification system kept at a constant voltage and gain throughout the experiment.

\section{ITS1 sequencing}

DNA sequencing of the internal transcribed spacer 1 (ITS1) region was performed for selected C. geophilum isolates. Total DNA was extracted from mycelial cultures grown on PDA using the DNeasy Plant Mini Kit (Qiagen GmbH, Hilden, Germany) according to the manufacturer's instructions except for an initial incubation in lysis buffer $A B 1$ at $75^{\circ} \mathrm{C}$ for $3 \mathrm{~h}$ with occasional vortexing. Polymerase chain reaction (PCR) amplification of the ITS1 region was carried out using the fungus-specific oligonucleotide primer ITS1F (5'-CTTGGTCATTTAGAGGAAGTAA-3'; Gardes and Bruns 1993) and the universal primer ITS4 (5'-TCCTCCGCTTATTGATATGC-3'; White et al. 1990) in $50 \mu \mathrm{L}$ reactions containing approximately $20 \mathrm{ng}$ of extracted DNA, $500 \mathrm{nM}$ of each of the oligonucleotide primers ITS1F and ITS4, $250 \mu \mathrm{M}$ of each dNTP, $2 \mathrm{mM} \mathrm{MgCl}_{2}$, and $2.5 \mathrm{U}$ of Taq DNA polymerase (Fermentas GmbH, St. Leon-Rot, Germany) in $1 \times$ Taq buffer with $\mathrm{KCl}$ (Fermentas $\mathrm{GmbH}$, St.
Leon-Rot, Germany). The following PCR temperature profile was used: initial denaturation at $96^{\circ} \mathrm{C}$ for $2 \mathrm{~min} ; 20$ cycles of $94{ }^{\circ} \mathrm{C}$ for $30 \mathrm{~s}, 56{ }^{\circ} \mathrm{C}$ for $1 \mathrm{~min}$ and $72{ }^{\circ} \mathrm{C}$ for $1 \mathrm{~min}$; final extension at $72{ }^{\circ} \mathrm{C}$ for $10 \mathrm{~min}$. PCR products were examined by agarose gel electrophoresis and sequenced using the $\mathrm{ABI}$ BigDye $^{\circledR}$ Terminator reaction mixture and an ABI PRISM ${ }^{\circledR}$ 3730 XL DNA Analyzer (Applied Biosystems, Darmstadt, Germany) by STAB VIDA (Setúbal, Portugal).

Data analysis

Histograms of PI fluorescence intensity were obtained and evaluated using FloMax software v2.4d (Partec GmbH, Münster, Germany), and the genome size (in picogram) of each sample was determined according to the following formula:

DNA content of sample nuclei

$$
=\frac{\text { Mean } \mathrm{G}_{0} / \mathrm{G}_{1} \text { fluorescence of sample nuclei }}{\text { Mean } \mathrm{G}_{0} / \mathrm{G}_{1} \text { fluorescence of reference nuclei }} \times 1.16
$$

The reliability of the genome size measurements was verified by evaluating the quality of the flow cytometry histograms based on the coefficient of variation $(\mathrm{CV})$ of the $\mathrm{G}_{0} / \mathrm{G}_{1}$ peaks and the background debris, and the $\mathrm{CV}$ of the genome size estimation of each isolate based on three independent measurements.

As ANOVA assumptions were not met, differences in genome size between populations were evaluated by a Kruskal-Wallis one-way analysis of variance by ranks $(H$ test) with a significance level of $P<0.05$ using SigmaPlot v12.0 (Systat Software Inc., San Jose, CA, USA). A contingency test was performed to assess the association between ploidy level and ecological background using the Fisher's exact test for count data as implemented in R v2.15.1 ( $\mathrm{R}$ Core Team 2012). Genome size data were downloaded from the Fungal Genome Size Database (FGSD; Kullman et al. 2005) and included all records available in October 2012, with a mean value calculated for each species upon the occurrence of multiple entries.

Forward and reverse DNA sequences of the ITS1 region were edited and aligned using Bioedit v7.1.11 (Hall 1999) and compared with all fungal sequences available through the BLAST Network Service (National Center for Biotechnology Service, NCBI; http://www.ncbi.nlm.nih.gov/ BLAST) and the UNITE database (Kõljalg et al. 2005) using the BLASTn algorithm (Altschul et al. 1997). All generated DNA sequence data have been deposited with the EMBL/GenBank Data Libraries and are available under accession nos. KC894709-KC894711. 


\section{Results}

Clear symmetrical $\mathrm{G}_{0} / \mathrm{G}_{1}$ fluorescence intensity peaks of both the fungal and the plant reference nuclei were obtained (see Fig. 1), with a mean CV value of the fungal $\mathrm{G}_{0} / \mathrm{G}_{1}$ peaks of $7.34 \%$, falling within the range of values reported in similar works (e.g., Sędzielewska et al. 2011). No mean $\mathrm{CV}$ measures of individual genome size estimations exceeded $10 \%$ (see Table S1). The endopolyploid nature of $R$. sativus (Kudo and Kimura 2001) did not affect the analysis as only the peak corresponding to the $2 \mathrm{C}$ nuclei, which is used for genome size estimation, appeared on the scale set (see Fig. 1).

The mean DNA content per nucleus across the triplicate measurements for each $C$. geophilum isolate varied between $0.170 \pm 0.010 \mathrm{pg}(166 \pm 10 \mathrm{Mbp})$ and $0.439 \pm 0.040 \mathrm{pg}(430 \pm$ $39 \mathrm{Mbp}$ ), with an overall median and median absolute deviation (MAD) across isolates of $0.209 \pm 0.012 \mathrm{pg}(205 \pm$ $12 \mathrm{Mbp}$ ) (see Table 1, Table S1 and Fig. 2). As the distribution of the average DNA content per isolate is skewed towards the lower end of its range and C. geophilum is assumed to be a haploid organism with $n=6$ chromosomes
(Portugal et al. 2002), the majority of the isolates included in this study ( $85 \%$; see Fig. 2 and Table S1) are presumed to be haploid with an average mean DNA content per nucleus of $0.208 \pm 0.016 \mathrm{pg}(203 \pm 16 \mathrm{Mbp})$. An estimated DNA content of $0.246 \pm 0.027 \mathrm{pg}(241 \pm 27 \mathrm{Mbp})$ was obtained for the reference isolate $\mathrm{Cg} 1.58$ (see Table S1), in accordance with initial estimations based on preliminary genome sequencing results (M. Peters, personal communication). Six isolates had genome sizes suggesting variation in ploidy level within C. geophilum, with three isolates giving diploid and two isolates giving aneuploid estimates (see Fig. 1 and Table S1). Interestingly, one isolate (D70.1) was found to be mixoploid and displayed an approximately equal amount of haploid and diploid nuclei (see Fig. 1d and Table S1).

DNA sequences of ITS1 in isolates of each of the three ploidy classes (haploid: isolate C79.2, diploid: isolate A99.1, and aneuploid: isolate B57.3; see Table S1) were obtained to rule out misidentification of our fungal cultures and therefore taxonomic diversity having caused the observed variation in genome size. Average pairwise sequence similarity between the three ITS 1 sequences was $97 \%$, indicating a close phylogenetic relatedness of isolates with different ploidy levels, and
Fig. 1 Fluorescence intensities in flow cytometry analysis. Histograms of relative fluorescence intensities obtained through simultaneous flow cytometry analysis of propidium iodide-stained nuclei of C. geophilum (peaks 1 and 3) and R. sativus cv. Saxa (peak 2; internal reference standard with $2 \mathrm{C}=1.16 \mathrm{pg}$ or $1,135 \mathrm{Mb}$ ). Illustrative histograms are shown for the following ploidy classes: a haploid (isolate $\mathrm{Cg}$ 1.58), b diploid (isolate B5.1), c aneuploid (isolate B57.3), and d mixoploid (isolate D70.1). Peaks are marked as: $1, C$. geophilum nuclei at the $\mathrm{G}_{0} / \mathrm{G}_{1}$ phase; $2, R$. sativus nuclei at the $\mathrm{G}_{0} / \mathrm{G}_{1}$ phase; 3, diploid $C$. geophilum nuclei at the $\mathrm{G}_{0} / \mathrm{G}_{1}$ phase and haploid nuclei at the $\mathrm{G}_{2}$ phase. The inset table provides information on the mean channel number (the mean fluorescence intensity of stained nuclei), the DNA index (DI=mean channel number of sample/mean channel number of reference standard) and the coefficient of variation $(\mathrm{CV}, \%)$ of each peak a

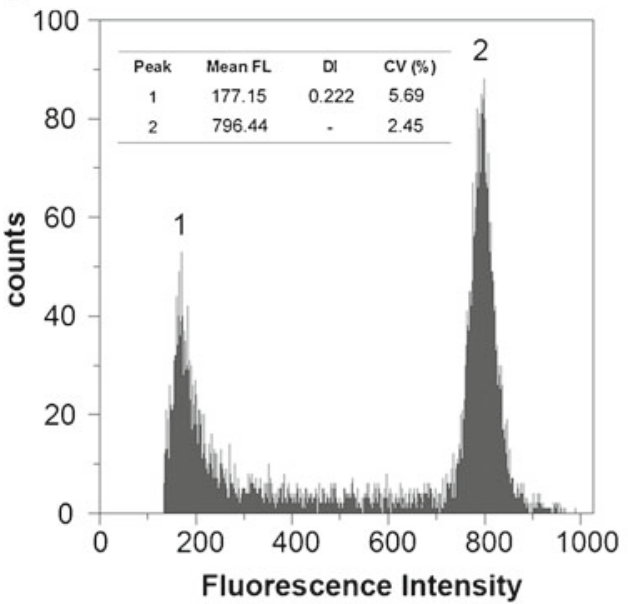

C

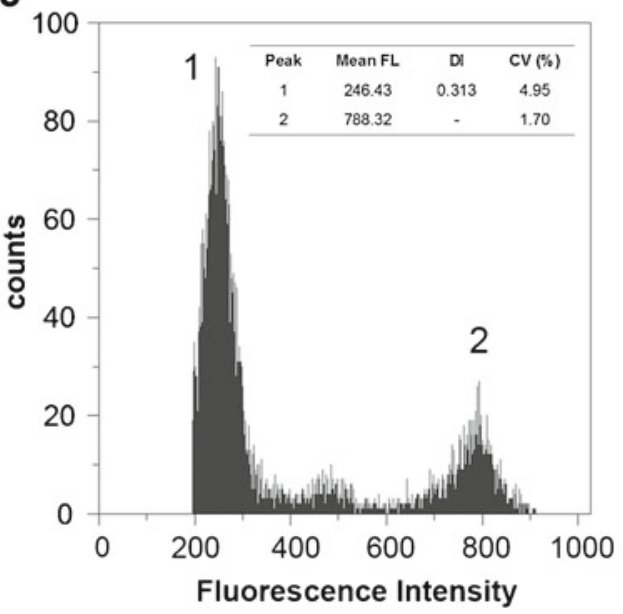

b

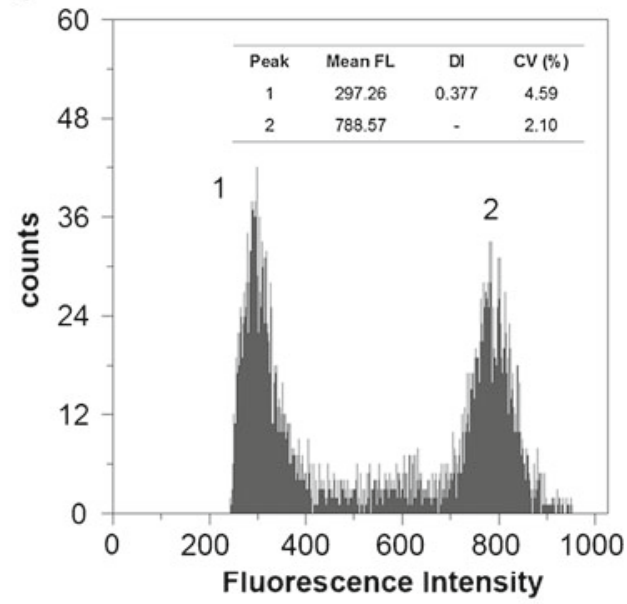

d

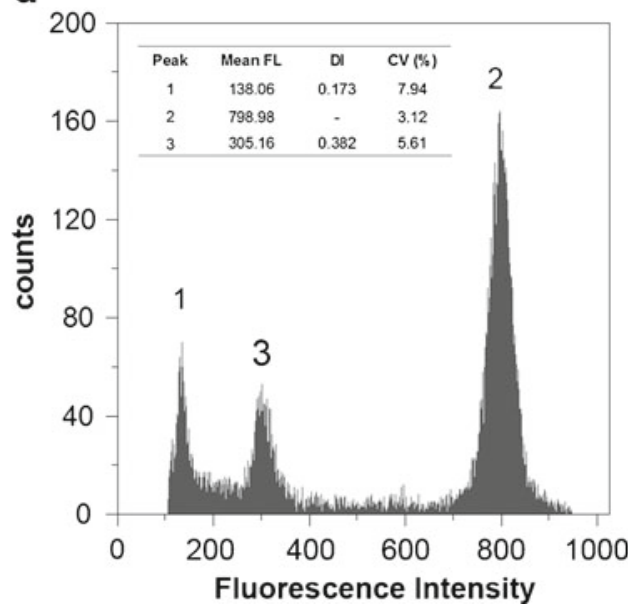


Table 1 Summary of genome sizes in C. geophilum

\begin{tabular}{|c|c|c|c|c|c|}
\hline \multirow[t]{2}{*}{ Population } & \multirow[t]{2}{*}{ Soil type } & \multirow[t]{2}{*}{ Ploidy level } & \multicolumn{2}{|c|}{ Nuclear DNA content } & \multirow[t]{2}{*}{$n$} \\
\hline & & & Mean \pm SD (pg) & Mean \pm SD (Mbp) & \\
\hline \multirow[t]{3}{*}{ Espinhosela } & \multirow[t]{3}{*}{ S } & Haploid & $0.199 \pm 0.01$ & $194 \pm 10$ & 9 \\
\hline & & Diploid & - & - & - \\
\hline & & Aneuploid & $0.283 \pm 0.03$ & $276 \pm 29$ & 1 \\
\hline \multirow[t]{3}{*}{ Nogueira } & \multirow[t]{3}{*}{ S } & Haploid & $0.218 \pm 0.01$ & $213 \pm 10$ & 9 \\
\hline & & Diploid & $0.410 \pm 0.03$ & $401 \pm 29$ & 1 \\
\hline & & Aneuploid & - & - & - \\
\hline \multirow[t]{3}{*}{ Rabal } & \multirow[t]{3}{*}{ NS } & Haploid & $0.213 \pm 0.01$ & $209 \pm 10$ & 8 \\
\hline & & Diploid & $0.421 \pm 0.03$ & $411 \pm 29$ & 1 \\
\hline & & Aneuploid & $0.361 \pm 0.01$ & $353 \pm 10$ & 1 \\
\hline \multirow[t]{3}{*}{ Aveleda } & \multirow[t]{3}{*}{ NS } & Haploid & $0.201 \pm 0.01$ & $196 \pm 10$ & 8 \\
\hline & & Diploid $^{\mathrm{a}}$ & $0.417 \pm 0.04$ & $409 \pm 39$ & 2 \\
\hline & & Aneuploid & - & - & - \\
\hline \multirow[t]{3}{*}{ All populations } & & Haploid & $0.208 \pm 0.01$ & $203 \pm 10$ & 34 \\
\hline & & Diploid & $0.416 \pm 0.01$ & $414 \pm 10$ & 4 \\
\hline & & Aneuploid & $0.322 \pm 0.06$ & $315 \pm 59$ & 2 \\
\hline
\end{tabular}

0.218 pg (213 Mbp) (see Table 1), with no significant difference in genome size between the populations (Kruskal-Wallis test, $\left.H_{3,31}=4.438, P=0.218\right)$. In addition, no significant association was found between ploidy level and edaphic background (Fisher's exact test, $P=0.604$ ).

\section{Discussion}

Although the important role that fungi play in ecosystem diversity and functioning is under active research (e.g., Read and Perez-Moreno 2003), until recently, there has been
Fig. 2 Genome size variation in C. geophilum. Histogram of nuclear DNA content (in picogram) estimated for 40 isolates of C. geophilum by propidium iodide flow cytometry

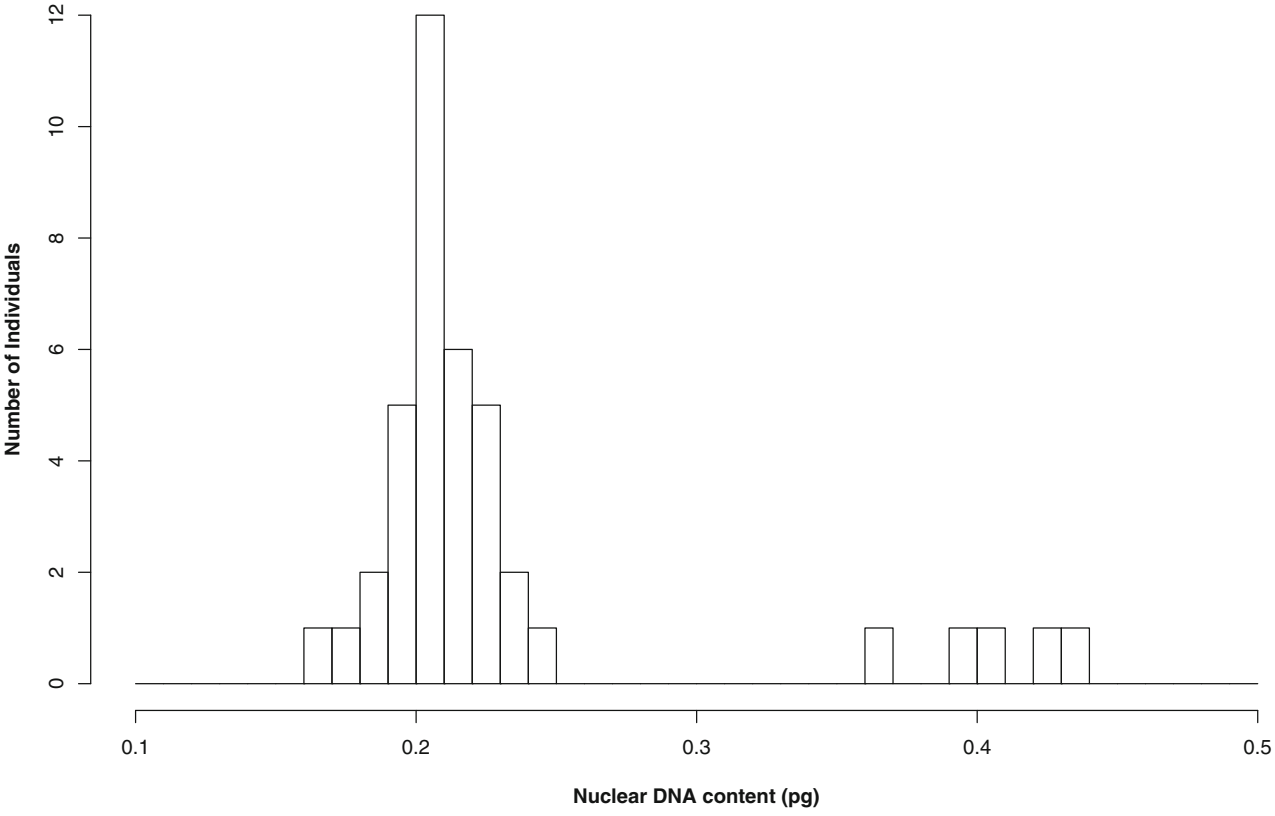




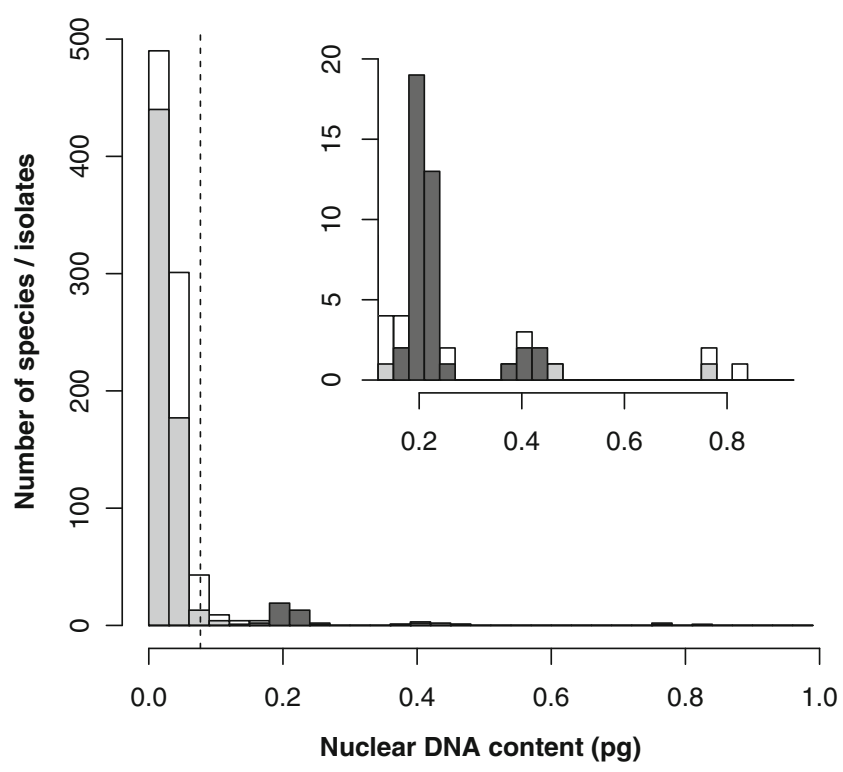

Fig. 3 Genome size variation among fungal species. Mean genome size in picogram of each species reported in the Fungal Genome Size Database (FGSD; open bars) with the distribution of Ascomycota highlighted (light gray) and the genome size estimates of $40 \mathrm{C}$. geophilum isolates (dark gray). Inset graph: detailed view of the size distribution for the upper range, including C. geophilum (colours as before). The 95th percentile of all species reported in the FGSD $(0.0795 \mathrm{pg})$ is marked as a vertical dashed line

relatively scarce information on genome structure and size for non-model fungal species despite its relevance for comparative biodiversity research (Gregory et al. 2007). Nevertheless, a growing body of evidence indicates large variation in genome size in the fungal kingdom. While about $90 \%$ of estimations range from 10 to $60 \mathrm{Mbp}$ (Gregory et al. 2007), extreme haploid genome sizes of up to $795 \mathrm{Mbp}$ have been reported for Scutellospora castanea (Glomeromycota; Hosny et al. 1998, Hijri and Sanders 2005). The Ascomycota are well represented throughout this range, with estimates of $7.7 \mathrm{Mbp}$ for Bulgaria inquinans (order Helotiales; Weber 1992) to $750 \mathrm{Mbp}$ for Neottiella vivida (order Pezizales; Kullman 2002).

Considering the range of genome sizes observed in the Ascomycota, our estimates of an average haploid genome size of $203 \mathrm{Mbp}$ in C. geophilum indicate that the genome size of this species is much larger than expected a priori and this holds even when extending our comparison to the whole fungal kingdom (see Fig. 3). Although large genome sizes are generally recorded for highly polyploid species (e.g., N. vivida has a ploidy level of 70; Kullman 2002), exceptionally large genome sizes have been observed in other haploid species (e.g., the haploid arbuscular mycorrhizal species Glomus etunicatum has a genome size of 750 Mbp; Hijri and Sanders 2005).

In a recent analysis of the underlying processes associated with genome size expansion within the Ascomycota, Kelkar and Ochman (2012) suggest that genetic drift, reflected through a decrease in gene density and a proliferation of introns, has played a significant role across many lineages on broad evolutionary time scales. The large genome size of $C$. geophilum might therefore result from ancestral genome size expansion driven by genetic drift, which would lead to a repeat-rich and relatively gene-poor genome. However, selective and neutral processes together are associated with genome size expansion within some lineages as observed by Kelkar and Ochman (2012) and others (see, e.g., Martin et al. 2010). Future analyses of the genome sequence of $C$. geophilum may provide more insights into whether its surprisingly large genome size is the consequence of genetic drift alone or in combination with selective processes.

Besides variation in genome size among the haploid $C$. geophilum isolates, variation in ploidy level was observed as four C. geophilum isolates were considered to be diploid (including the observed mixoploid) and two to be aneuploid based on our genome size estimations. Such intraspecific variation in genome size, including the variation among the isolates of a given ploidy level, is common among fungi. This variation often results from chromosome length polymorphisms and/or from gain/loss of complete chromosomes or sets thereof, as has been demonstrated in Cronartium quercuum (Anderson et al. 2010), Cryptococcus neformans (Hu et al. 2011), and Saccharomyces cerevisiae (Codón et al. 1998; Albertin et al. 2009).

Variation in genome size and the potential for genome plasticity can contribute to adaptation in heterogeneous environments. Differential selection across ploidy levels has been observed in different abiotic environments (e.g., Dhar et al. 2011) and increased ploidy has been suggested to provide a selective advantage in adaptation to new environmental conditions (Pawlowska and Taylor 2004; Ma et al. 2009). However, despite the strong selection pressure that is expected in serpentine soils and a report of possible influences of serpentine on the evolution of polyploids in $K$. arvensis (Koláŕ et al. 2012), we did not find significant differentiation in genome size between the $C$. geophilum populations included in this study, suggesting that genetic and demographic processes are more important in shaping the genome size variation of this species than environmental selection in the form of home soil chemistry. While these results suggest that variation in ploidy level is not related to serpentine tolerance in $C$. geophilum, the relatively large genome size-providing the potential for local adaptation to develop in vastly different environments - may still contribute to the wide ecological breadth, including the occurrence in serpentine soils, reported for this species.

Although unrelated to adaptation to serpentine soil conditions, it is noteworthy to state that the identification of diploid and mixed haploid/diploid C. geophilum isolates may indicate 
the occurrence of a cryptic mating or parasexual cycle in this presumed asexual fungal species. As first described for $A s$ pergillus nidulans (Pontecorvo et al. 1953), the standard parasexual cycle starts with the formation of a heterokaryon (plasmogamy) followed by a fusion of the two haploid genomes (karyogamy). The resulting diploid nuclei divide mitotically along with remaining haploid nuclei and may form a discrete sector or even propagate as separate diploid strains. However, the diploid nuclei may be unstable and produce haploid or aneuploid segregants through mitotic recombination and chromosomal nondisjunction. Our observation of diploid and mixed haploid/diploid C. geophilum isolates thus supports an earlier suggestion of a cryptic mating or parasexual cycle in $C$. geophilum based on the indirect observation of genetic recombination using DNA sequence or genetic marker data (Lobuglio and Taylor 2002; Douhan et al. 2007). A sexual stage in $C$. geophilum was also recently proposed by Spatafora et al. (2012) based on the large genetic diversity detected in this species and a close phylogenetic relationship with Glonium, for which a sexual stage has been identified. As sexual reproduction in fungi can be geographically isolated and therefore difficult to detect (O'Gorman et al. 2009; Spatafora et al. 2012), it is not surprising that we found only 6 in 40 isolates to deviate from a presumed haploid condition. However, the existence of a parasexual cycle is not the only possible explanation for the observed variance in ploidy level. Alternatively, this variance may be the result of an endopolyploidization process that involves recurrent cycles of DNA replication without cellular division and produces an increase of the genome content in the somatic line or it may reflect the existence of phylogenetically diverged lineages within a $C$. geophilum sensu lato species complex that was proposed by Douhan et al. (2007).

In conclusion, this study revealed C. geophilum to have one of the largest genome sizes so far measured in the Ascomycota, with a mean haploid genome size estimate of $0.208 \mathrm{pg}$ or $203 \mathrm{Mbp}$. Although within-species variation in genome size was detected, it was unrelated to the edaphic background of the isolates indicating that serpentine soil conditions do not affect genome sizes in C. geophilum. The observed variation in genome size, more specifically ploidy level, may however support the existence of a cryptic mating or parasexual cycle. As other explanations for this variation are possible, additional analyses are still required to confirm the presence and/or nature of a cryptic sexual stage in this widely distributed ectomycorrhizal species.

Acknowledgments We thank Dr. Martina Peter for providing us with the $C$. geophilum $\mathrm{Cg} 1.58$ reference isolate and Dr. Catarina Moura for her help with the isolation of $C$. geophilum from soil samples. This work was supported by research grant PTDC/BIA-BEC/100733/2008, funded by the European Union and the Fundação para a Ciência e a Tecnologia, awarded to Ludo Muller.

\section{References}

Albertin W, Marullo P (2012) Polyploidy in fungi: evolution after whole-genome duplication. Proc R Soc B 279:2497-2509

Albertin W, Marullo P, Aigle M, Bourgais A, Bely M, Dillmann C, De Vienne D, Sicard D (2009) Evidence for autotetraploidy associated with reproductive isolation in Saccharomyces cerevisiae: towards a new domesticated species. J Evol Biol 22:2157-2170

Altschul SF, Madden TL, Schaffer AA, Zhang J, Zhang Z, Miller W, Lipman DJ (1997) Gapped BLAST and PSI-BLAST: a new generation of protein database search programs. Nucleic Acids Res 25:3389-3402

Anderson CL, Kubisiak TL, Nelson CD, Smith JA, Davis JM (2010) Genome size variation in the pine fusiform rust pathogen Cronartium quercuum f.sp. fusiforme as determined by flow cytometry. Mycologia 102:1295-1302

Brady KU, Kruckeberg AR, Bradshaw HD Jr (2005) Evolutionary ecology of plant adaptation to serpentine soils. Annu Rev Ecol Evol S 36:243-266

Codón AC, Benítez T, Korhola M (1998) Chromosomal polymorphism and adaptation to specific industrial environments of Saccharomyces strains. Appl Microbiol Biot 49:154-163

Cui L, Wall PK, Leebens-Mack JH, Lindsay BG, Soltis DE, Doyle JJ, Soltis PS, Carlson JE, Arumuganathan K, Barakat A, Albert VA, Ma H, dePamphilis CW (2006) Widespread genome duplications throughout the history of flowering plants. Genome Res 16:738 749

Dhar R, Sägesser R, Weikert C, Yuan J, Wagner A (2011) Adaptation of Saccharomyces cerevisiae to saline stress through laboratory evolution. J Evol Biol 24:1135-1153

Doležel J, Greilhuber J, Lucretti S, Meister A, Lysák M, Nardi L, Obermayer R (1998) Plant genome size estimation by flow cytometry: inter-laboratory comparison. Ann Bot 82(Suppl A):1726

Douhan GW, Rizzo DM (2005) Phylogenetic divergence in a local population of the ectomycorrhizal fungus Cenococcum geophilum. New Phytol 166:263-271

Douhan GW, Martin DP, Rizzo DM (2007) Using the putative asexual fungus Cenococcum geophilum as a model to test how species concepts influence recombination analyses using sequence data from multiple loci. Curr Genet 52:191-201

Fernandez-Toiran LM, Agueda B (2007) Fruit bodies of Cenococcum geophilum. Mycotaxon 100:109-114

Galbraith DW, Harkins KR, Maddox JM, Ayres NM, Sharma DP, Firoozabady E (1983) Rapid flow cytometric analysis of the cell cycle in intact plant tissues. Science 220:1049-1051

Gardes M, Bruns TD (1993) ITS primers with enhanced specificity for basidiomycetes - application to the identification of mycorrhizae and rusts. Mol Ecol 2:113-118

Gonçalves SC, Portugal A, Gonçalves MT, Vieira R, Martins-Loução MA, Freitas H (2007) Genetic diversity and differential in vitro responses to $\mathrm{Ni}$ in Cenococcum geophilum isolates from serpentine soils in Portugal. Mycorrhiza 17:677-686

Gonçalves SC, Martins-Loução MA, Freitas H (2009) Evidence of adaptive tolerance to nickel in isolates of Cenococcum geophilum from serpentine soils. Mycorrhiza 19:221-230

Gregory TR, Nicol JA, Tamm H, Kullman B, Kullman K, Leitch IJ, Murray BG, Kapraun DF, Greilhuber J, Bennett MD (2007) Eukaryotic genome size databases. Nucl Acids Res 35:D332-D338

Hall TA (1999) BioEdit: a user-friendly biological sequence alignment editor and analysis program for Windows 95/98/NT. Nucl Acids Symp Ser 41:95-98

Hijri M, Sanders JR (2005) Low gene copy number shows that arbuscular mycorrhizal fungi inherit genetically different nuclei. Nature 433:160-163 
Hilton C, Markie D, Corner B, Rikkerink E, Poulter R (1985) Heat shock induces chromosome loss in the yeast Candida albicans. Mol Gen Genet 200:162-168

Hosny M, Gianinazzi-Pearson V, Dulieu H (1998) Nuclear DNA content of 11 fungal species in Glomales. Genome 41:422-428

Hu G, Wang J, Choi J et al (2011) Variation in chromosome copy number influences the virulence of Cryptococcus neoformans and occurs in isolates from AIDS patients. BMC Genomics 12:526

Ibrahim AS, Magee BB, Sheppard DC, Yang M, Kauffman S, Becker J, Edwards JE Jr, Magee PT (2005) Effects of ploidy and mating type on virulence of Candida albicans. Infect Immun 73:7366-7374

Kazazian HH Jr (2004) Mobile elements: drivers of genome evolution. Science 303:1626-1632

Kelkar YD, Ochman H (2012) Causes and consequences of genome expansion in fungi. Genome Biol Evol 4:13-23

Koláŕ F, Fér T, Štech M, Trávníček P, Dušková E, Schönswetter P, Suda J (2012) Bringing together evolution on serpentine and polyploidy: spatiotemporal history of the diploid-tetraploid complex of Knautia arvensis (Dipsacaceae). PLoS One 7:e39988

Kõljalg U, Larsson KH, Abarenkov K, Nilsson RH, Alexander IJ, Eberhardt U, Erland S, Høiland K, Kjøller R, Larsson E, Pennanen T, Sen R, Taylor AFS, Tedersoo L, Vrålstad T, Ursing BM (2005) UNITE: a database providing web-based methods for the molecular identification of ectomycorrhizal fungi. New Phytol 166:1063-1068

Kudo N, Kimura Y (2001) Flow cytometric evidence for endopolyploidy in seedlings of some Brassica species. Theor App Genet 102:104-110

Kullman B (2002) Nuclear DNA content, life cycle and ploidy in two Neottiella species (Pezizales, Ascomycetes). Persoonia 18:103-115

Kullman B, Tamm H, Kullman K (2005) Fungal genome size database. http://www.zbi.ee/fungal-genomesize

LoBuglio KF (1999) Cenococcum. In: Cairney JWG, Chambers SM (eds) Ectomycorrhizal fungi: Key genera in profile. Springer, Berlin, pp 287-309

LoBuglio KF, Taylor J (2002) Recombination and genetic differentiation in the mycorrhizal fungus Cenococcum geophilum Fr. Mycologia 94:772-780

Loureiro J, Rodriguez E, Doležel J, Santos C (2007) Two new nuclear isolation buffers for plant DNA flow cytometry: a test with 37 species. Ann Bot 100:875-888

Ma LJ, Ibrahim AS, Skory C et al (2009) Genomic analysis of the basal lineage fungus Rhizopus oryzae reveals a whole-genome duplication. PLoS Genetics 5:e1000549

Martin F, Kohler A, Murat C et al (2010) Périgord black truffle genome uncovers evolutionary origins and mechanisms of symbiosis. Nature 464:1033-1038

O'Gorman CM, Fuller HT, Dyer PS (2009) Discovery of a sexual cycle in the opportunistic fungal pathogen Aspergillus fumigatus. Nature 457:471-474

Panaccione DG, Sheets NL, Miller SP, Cumming JR (2001) Diversity of Cenococcum geophilum isolates from serpentine and nonserpentine soils. Mycologia 93:645-652

Pawlowska TE, Taylor JW (2004) Organization of genetic variation in individuals of arbuscular mycorrhizal fungi. Nature 427:733-737
Poláková S, Blume C, Zárate JA, Mentel M, Jørck-Ramberg D, Stenderup J, Piskur J (2009) Formation of new chromosomes as a virulence mechanism in yeast Candida glabrata. Proc Natl Acad Sci USA 106:2688-2693

Pontecorvo G, Roper JA, Forbes E (1953) Genetic recombination without sexual reproduction in Aspergillus niger. J Gen Microbiol $8: 198-210$

Portugal A, Gonçalves SC, Vieira R, Freitas H (2002) Chromosome number in the ectomycorrhizal fungus Cenococcum geophilum from ultramafic soils of NE Portugal. Nucleus 45:14-18

Proctor J (1999) Toxins, nutrient shortage and droughts: the serpentine challenge. Trends Ecol Evol 14:334-335

R Core Team (2012) R: A language and environment for statistical computing. R Foundation for Statistical Computing, Vienna, Austria. ISBN 3-900051-07-0. http://www.R-project.org/

Raffaele S, Kamoun S (2012) Genome evolution in filamentous plant pathogens: why bigger can be better. Nature 10:417-430

Read DJ, Perez-Moreno J (2003) Mycorrhizas and nutrient cycling in ecosystems - a journey towards relevance? New Phytol 157:475-492

Sędzielewska K, Fuchs J, Temsch E, Baronian K, Watzke R, Kunze G (2011) Estimation of the Glomus intraradices nuclear DNA content. New Phytol 192:794-797

Smith SE, Read DJ (2008) Mycorrhizal symbiosis, 3rd edn. Academic, San Diego

Soltis DE, Soltis PS (1999) Polyploidy: recurrent formation and genome evolution. Trends Ecol Evol 14:348-352

Spatafora JW, Owensby CA, Douhan GW, Boehm EWA, Schoch CL (2012) Phylogenetic placement of the ectomycorrhizal genus Cenococcum in Gloniaceae (Dothideomycetes). Mycologia 104:758-765

Taylor JW, Jacobson DJ, Fisher MC (1999) The evolution of asexual fungi: reproduction, speciation and classification. Annu Rev Phytopathol 37:197-246

Trappe JM (1964) Mycorrhizal hosts and distribution of Cenococcum graniforme. Lloydia 27:100-106

Weber E (1992) Untersuchungen zu Fortpflanzung und Ploidie verschiedener Ascomyceten. Biblioth Mycol 140:1-186

Welker DL, Williams KL (1980) Mitotic arrest and chromosome doubling using thiabendazole, cambendazole, nocodazole and ben late in the slime mould Dictyostelium discoideum. J Gen Microbiol 116:397-407

White TJ, Bruns TD, Lee SB, Taylor JWE (1990) Amplification and direct sequencing of fungal ribosomal RNA Genes for phylogenetics. In: Innis $\mathrm{N}$, Gelfand $\mathrm{D}$, Sninsky $\mathrm{J}$, White $\mathrm{T}$ (eds) PCR - protocols and applications - a laboratory manual. Academic, New York, pp 315-322

Whitney KD, Garland T Jr (2010) Did genetic drift drive increases in genome complexity? PLoS Genet 6:e1001080

Wu BY, Nara K, Hogetsu T (2005) Genetic structure of Cenococcum geophilum populations in primary successional volcanic deserts on Mount Fuji as revealed by microsatellite markers. New Phytol $165: 285-293$ 